\title{
Study on Vertex Interval Determination for Consistent Calculation of Coastline Length
}

\author{
H. S. WOO ${ }^{\text {a }}$, K. S. Kwon ${ }^{\text {a, } * \text {, B. G. Kim }}{ }^{\text {a }}$ \\ ${ }^{a}$ Dept. of Geoinformatic Engineering, Inha University, Inha Street, Incheon, Korea - (heesook@inha.edu, \\ kskwon02@gmail.com, byungkim@inha.ac.kr)
}

\author{
Commission V, WG V/4
}

KEY WORDS: Coastline Length, Natural coastline, Vertex Interval, Consistent, Generalization, National policy

\begin{abstract}
:
Coastline extraction and decision have important implications for efficient land management and national policy formulation. However, coastlines extracted without certain criteria are difficult to obtain consistent results for the same region, and therefore, have a lot of restrictions on land management and application. For example, in some South Korea coastlines surveyed in this study, it was confirmed that there is a large difference in coastline lengths calculated for the same area depending on how the vertex interval is set. In this study, we propose and discuss the guidelines to enable consistent and accurate coastline extraction for the same area. The consistency of coastline output can be ensured only by the coastline calculation method using vertex interval criterion considering regional and coastline characteristics. This research content is expected to contribute to efficient land management and national policy establishment and progress.
\end{abstract}

\section{INTRODUCTION}

The coastline is an important criterion for determining the shape of the nation. In recent years, the natural coastline is gradually decreasing due to several environmental factors such as climate change, sea level rise, coastal development and so on. In case of South Korea, the percentages of the natural coastline and the artificial coastline was $74 \% 26 \%$, respectively, among the total coastline as of 2010 . However, the percentages of the two types of coastlines were changed to $66 \%$ and $34 \%$, respectively, as of 2014 (Sin, 2010) (Choi et al, 2014).

Several countries adopt policies for integrated coastal management, in order to protect the coast and to manage the natural coastline at national level. In the United States, the CZMA (Coastal Zone Management Act) was enacted in 1972 as a coastal zone management program to balance development and conservation (Choi, 2005). In China, the National Maritime Functional Zone is being implemented from 2012 with the aim of expanding maritime management functions and marine protected areas (Sin, 2013). South Korea also established the second integrated coastal management plan in 2016 to balance the development and conservation of coastal space (Kim, 2016).
This applies the management subject to the concept of side and line and classified into 5 types (Natural coastal beach, artificial coastal beach, natural coastal line, artificial coastal line, intertidal zone). We set the goal (plan) for each type to manage the coast.

For such coastal management plan, coastal lines are used as a basis for predicting the size of coastal development needs and estimating budgets for integrated coastal management. The use of consistent coastlines has important implications for efficient land management and national policy formulation. Also, extracting coastlines without consistent criteria may make it difficult to obtain accurate and consistent coastline values for the same region, and therefore, such extraction may lead to a lot of restrictions on land management and other applications.

The purpose of this study is to identify the change of coastline length according to the vertex interval, and to derive appropriate vertex interval and consistent coastline extraction method for consistent coastline extraction.

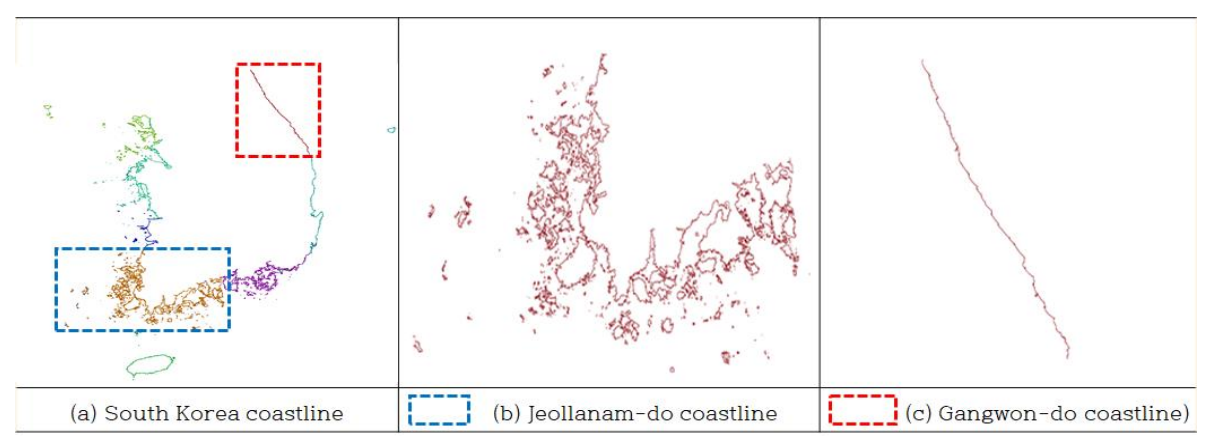

Figure 1. Coastline for test area (a. South Korean coastline, b. Jeollanam-do coastline, c. Gangwon-do coastline

* Corresponding author 


\section{RESEARCH CONTENTS AND RESULTS}

The total length of the South Korean coastline is $13,463 \mathrm{~km}$. The length of the natural coastline occupies $66 \%$ and the length of the artificial coastline occupies $34 \%$ compared to the length of the entire coastline. Figure1(a) shows the length of the entire Korean coastline, and Figure1(b) and Figure1(c) are the enlargements of Jeollanam-do coastline(blue box) and Gangwon-do coastline(red box) in Figure1(a).

We used the Open Source GIS (Geographic Information System) tool to confirm the change of coastline according to the vertex interval for two regions with distinct geographic features (Jeollanam-do vs Gangwon-do).

As shown in Figure 1 (b), Jeollanam-do has a complex coastline and many islands. In case of this area the natural coastline length is $32 \%$ and the artificial coastline length is $13 \%$ compared to the total coastline length. As shown in Figure 1 (c), the coastline of Gangwon-do is monotonous. In case of this area the natural coastline length is $2 \%$ and the artificial coastline length is $1 \%$ compared to the total coastline length.

For two test regions, table 1 and 2 shows the number of vertices according to different vertex interval. The coastline was exploded into 11 vertex intervals considering the minimum vertex interval $(>0.01)$ and the maximum vertex interval $(<1000)$. And tables 1 and 2 are denoted by number of Vertex interval, ratio of verticex number, and Accumulation rate of vertices number, which form each vertex interval.

In case of the number of vertices with the length of $0.5 \mathrm{~m} \sim 1 \mathrm{~m}$ (gray blank), the coastline of Jeollanam-do is more than twice as much as Gangwon-do. This is because the terrain is complicated when Jeollanam-do is compared to Gangwon-do.
Figure 2 compares the $0.5 \mathrm{~m} \sim 1 \mathrm{~m}$ sections with vertex interval for the similar terrain of the two areas. As shown in Fig. 2 (a), Jeollanam-do area is generally depicted densely in the curve section and the straight section. The Gangwon-do area is described more concisely than the Jeollanam-do curve section, and it is confirmed that the vertices with such interval are not used in some straight sections.

(a) Jeollanam-do

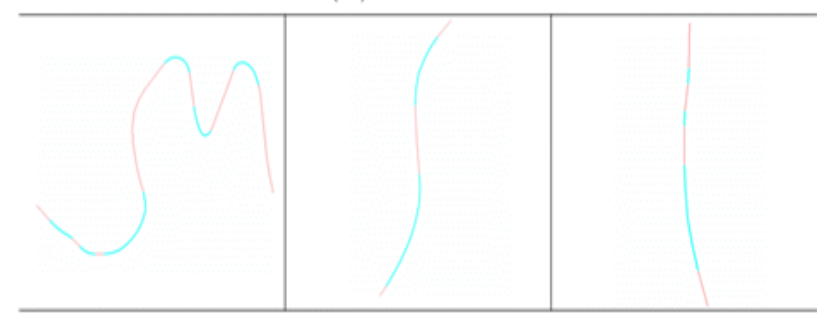

(b) Gangwon-do

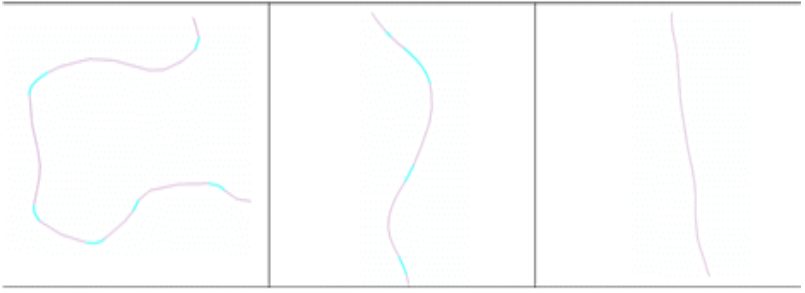

Figure 2. Comparison of coastline vertex interval (0.1m 0.5m section terrain a. Jeollanam-do, b. Gangwon-do)

\begin{tabular}{c|c|c|c|c|c|c|c|c|c|c|c}
\hline $\begin{array}{c}\text { Vertex interval } \\
\text { (meter) }\end{array}$ & 0.01 & 0.05 & 0.1 & 0.5 & 1 & 5 & 10 & 50 & 100 & 500 & 1000 \\
\hline $\begin{array}{c}\text { Number of Vertex } \\
\text { interval }\end{array}$ & 0 & 91437 & 227687 & 1685553 & 1233885 & 1310254 & 127740 & 74381 & 4227 & 907 & 9 \\
\hline $\begin{array}{c}\text { Ratio of vertices } \\
\text { number (\%) }\end{array}$ & 0.00 & 1.92 & 4.79 & 35.44 & 25.94 & 27.55 & 2.69 & 1.56 & 0.09 & 0.02 & 0.00 \\
\hline $\begin{array}{c}\text { Accumulation rate of } \\
\text { vertices number (\%) }\end{array}$ & 0.00 & 1.92 & 6.71 & 42.15 & 68.09 & 95.64 & 98.33 & 99.89 & 99.98 & 100.00 & 100.00 \\
\hline
\end{tabular}

Table 1. The number of vertex according to different vertex interval (Jeollanam-do)

\begin{tabular}{c|c|c|c|c|c|c|c|c|c|c|c}
\hline $\begin{array}{c}\text { Vertex interval } \\
\text { (meter) }\end{array}$ & 0.01 & 0.05 & 0.1 & 0.5 & 1 & 5 & 10 & 50 & 100 & 500 & 1000 \\
\hline $\begin{array}{c}\text { Number of Vertex } \\
\text { interval }\end{array}$ & 76 & 1307 & 3311 & 46349 & 77330 & 94281 & 5871 & 3804 & 473 & 183 & 3 \\
\cline { 1 - 5 } $\begin{array}{c}\text { Ratio of vertices } \\
\text { number } \%)\end{array}$ & 0.03 & 0.56 & 1.42 & 19.89 & 33.19 & 40.47 & 2.52 & 1.63 & 0.20 & 0.08 & 0.00 \\
\hline $\begin{array}{c}\text { Accumulation rate of } \\
\text { vertices number (\%) }\end{array}$ & 0.03 & 0.59 & 2.01 & 21.91 & 55.10 & 95.56 & 98.08 & 99.72 & 99.92 & 100.00 & 100.00 \\
\hline
\end{tabular}

Table 2. The number of vertex according to different vertex interval (Gangwon-do) 
(a) Natural coastline ratio of Jeollanam-do

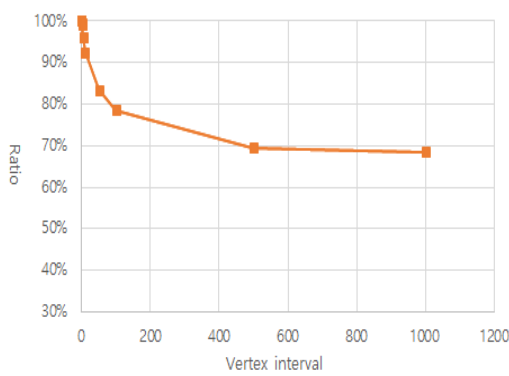

(c) Natural coastline ratio of Gangwon-do

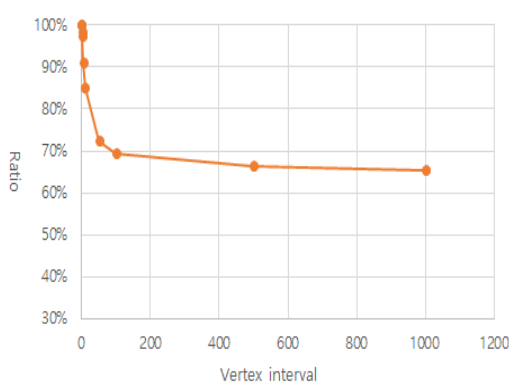

(b) Artificial coastline ratio of Jeollanam-do

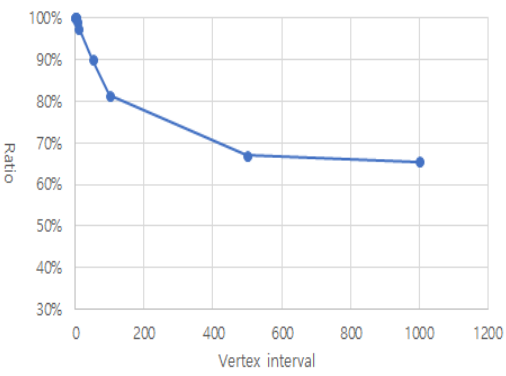

(d) Artificial coastline ratio of Gangwon-do

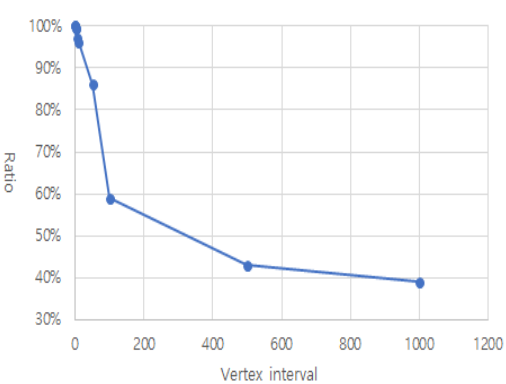

Figure 3. Coastline length change rate according to generalization $[0.01 \mathrm{~m} \sim 1000 \mathrm{~m}]$

For the two regions, it is classified into 11 grades $[0.01 \mathrm{~m}$, $0.05 \mathrm{~m}, 0.1 \mathrm{~m}, 0.5 \mathrm{~m}, 1 \mathrm{~m}, 5 \mathrm{~m}, 10 \mathrm{~m}, 50 \mathrm{~m}, 100 \mathrm{~m}, 500$, and $1000 \mathrm{~m}]$ based on the minimum vertex interval and maximum vertex interval. Next, we calculated the rate of change of the natural and artificial coastline according to generalization. As a result, it was confirmed that the coastline length of more than $99 \%$ of the total coastline length converges at the vertex interval of less than $1 \mathrm{~m}$, for both regions. Figure 3 shows that the coastline length converges to less than $70 \%$ of the total coastline length at the vertex interval of $200 \mathrm{~m}$.

We investigated the ratio of change of length according to the generalization of vertex interval in more detail. Table 3 shows the result of further subdividing the $1 \mathrm{~m} \sim 10 \mathrm{~m}$ grading region, whose length decreases sharply, into 10 grades $[1 \mathrm{~m}, 2 \mathrm{~m}, 3 \mathrm{~m}$, $4 \mathrm{~m}, 5 \mathrm{~m}, 6 \mathrm{~m}, 7 \mathrm{~m}, 8 \mathrm{~m}, 9 \mathrm{~m}, 10 \mathrm{~m}]$.

\begin{tabular}{|c|c|c|c|c|c|c|c|c|c|c|}
\hline \multirow[b]{2}{*}{$\begin{array}{l}\text { Vertex } \\
\text { interval }\end{array}$} & \multicolumn{4}{|c|}{ Jeollanam-do } & \multirow[b]{2}{*}{ All Length } & \multicolumn{4}{|c|}{ Gangwon-do } & \multirow[b]{2}{*}{ All Length } \\
\hline & $\begin{array}{l}\text { Natural } \\
\text { coastline } \\
\text { (meter) }\end{array}$ & $\begin{array}{c}\text { Ratio } \\
\text { (\%) }\end{array}$ & $\begin{array}{l}\text { Artificial } \\
\text { coastline } \\
\text { (meter) }\end{array}$ & $\begin{array}{c}\text { Ratio } \\
(\%)\end{array}$ & & $\begin{array}{l}\text { Natural } \\
\text { coastline } \\
\text { (meter) }\end{array}$ & $\begin{array}{c}\text { Ratio } \\
\text { (\%) }\end{array}$ & $\begin{array}{l}\text { Artificial } \\
\text { coastline } \\
\text { (meter) }\end{array}$ & $\begin{array}{c}\text { Ratio } \\
\text { (\%) }\end{array}$ & \\
\hline All & 4783565.913 & 100 & 1959666.783 & 100 & 6743232.696 & 286551.937 & 100 & 115353.613 & 100 & 401905.550 \\
\hline 1 & 4727374.135 & 99 & 1955395.775 & 100 & 6682769.909 & 281525.663 & 98 & 115076.428 & 99 & 396602.090 \\
\hline 2 & 4679468.692 & 98 & 1950099.349 & 100 & 6629568.041 & 277235.002 & 96 & 114674.356 & 98 & 391909.358 \\
\hline 3 & 4635851.557 & 97 & 1945103.112 & 99 & 6580954.668 & 273458.641 & 94 & 114319.514 & 98 & 387778.155 \\
\hline 4 & 4595578.221 & 96 & 1940004.407 & 99 & 6535582.629 & 270231.797 & 92 & 113929.349 & 97 & 384161.146 \\
\hline 5 & 4558351.616 & 96 & 1934507.787 & 99 & 6492859.404 & 267451.491 & 91 & 113574.867 & 97 & 381026.357 \\
\hline 6 & 4524356.852 & 95 & 1929013.562 & 98 & 6453370.414 & 264572.802 & 90 & 113256.902 & 96 & 377829.704 \\
\hline 7 & 4492872.044 & 94 & 1923725.755 & 98 & 6416597.799 & 262151.745 & 88 & 112940.930 & 96 & 375092.676 \\
\hline 8 & 4463439.920 & 94 & 1918995.248 & 98 & 6382435.169 & 259732.189 & 87 & 112616.740 & 96 & 372348.929 \\
\hline 9 & 4435740.581 & 93 & 1914600.871 & 98 & 6350341.452 & 257815.986 & 86 & 112345.338 & 96 & 370161.324 \\
\hline 10 & 4410562.882 & 93 & 1910556.900 & 97 & 6321119.783 & 255820.218 & 85 & 112002.521 & 96 & 367822.739 \\
\hline
\end{tabular}

Table 3. Results for generalization of Jeollanam-do \& Gangwon-do [1m 10m sections] 
(a) Natural coastline ratio of Jeollanam-do

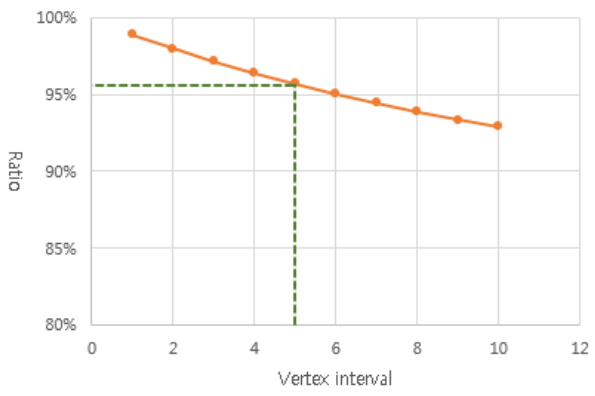

(c) Natural coastline ratio of Gangwon-do

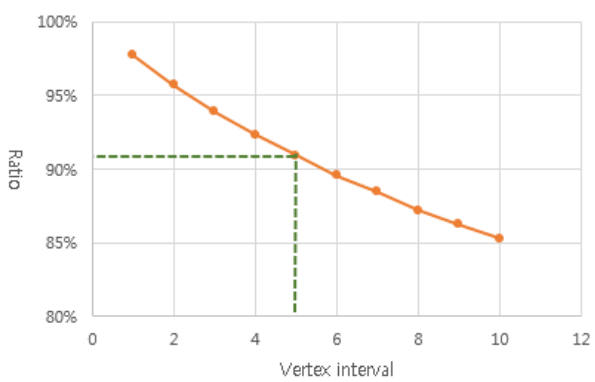

(b) Artificial coastline ratio of Jeollanam-do

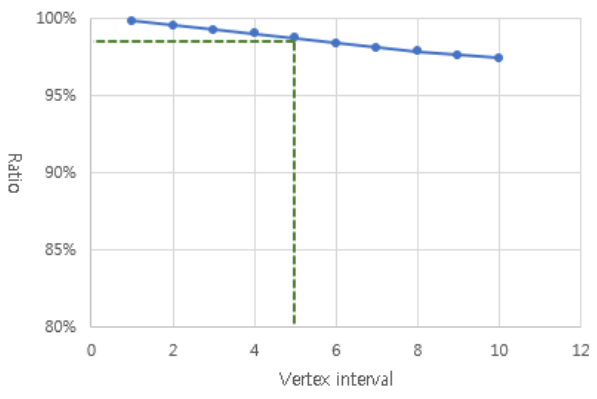

(d) Artificial coastline ratio of Gangwon-do

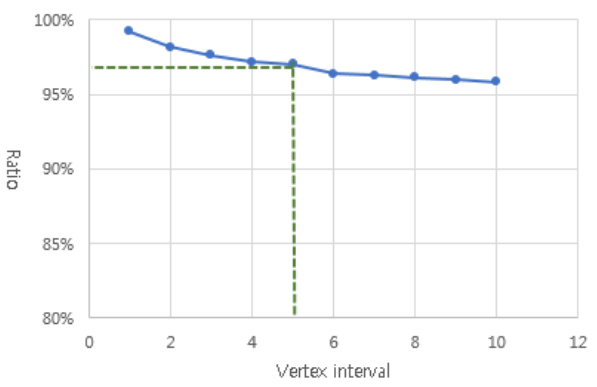

Figure 4. Coastline length change rate according to generalization [1m 10m sections]

Looking at the artificial coastline, the decrease rate of decrease is generally lower than that of the natural coastline. At the vertex interval of $10 \mathrm{~m}$, the artificial coastline length of the both regions converged more than $96 \%$. On the other hand, at the vertex interval of $5 \mathrm{~m}$, the natural coastline length of the Jeollanam-do converged more than $96 \%$ compared to the total coastline length, but Gangwon-do was less than 91\%. At the vertex interval of $10 \mathrm{~m}$, the natural coastline length of the Gangwon-do Gangwon-do was less than $85 \%$.

Compared to Jeollanam-do, the natural coastline length of Gangwon-do is decreasing rapidly as the vertex interval is widened. It is confirmed that the natural coastline length change rate is more sensitive to the vertex interval than the artificial coastline.

\section{CONCLUSIONS}

This study has confirmed that there is a large difference in coastline length depending on how to set the vertex interval. We have found that in some Korean coastlines surveyed in this study, there is a large difference in the length of the coastline calculated in the same area according to the vertex interval. In other words, the length of the coastline calculated using the vertex interval greater than $0.5 \mathrm{~m}$ showed a large difference compared with the reference value, and the length using the vertex interval smaller than 0.5 was almost the same as the reference value. Especially, the length of coastline using the vertex interval was slightly different according to regional characteristics, but sharply decreased by $88 \%$ compared to the standard value. This means that it is important to set appropriate vertex interval values for accurate and consistent coastline extraction because a lot of differences may occur in the result of the coastlines extracted according to the vertex interval. It also shows that appropriate coastline extraction methods for consistent results need to be discussed. And this suggests that coastline length should be consistent when used as a basis for establishing policies.
Under the circumstance that natural coasts are reduced due to environmental changes and coastal activities, the establishment and implementation of consistent national policies are required for balanced coastal development.

In order to protect the coast and to manage the natural coastline at national level, various policies are being implemented such as natural coastal management policy. The coastline as a basic data for preserving natural coasts has important meaning for ensuring equity in various policies such as natural coastal management policy.

As shown in this study, extracting coastlines without consistent criteria are difficult to ensure consistency of output according to topographical characteristics and calculation method. In future, it will be necessary to study the minimum vertex interval calculation standard for consistent coastline calculation considering various regional characteristics. Consistency of the coastline that determines the territory of the national will contribute to systematic and consistent national policy formulation and progress. In addition, it is necessary to examine the possibility of deducing consistent vertex interval using fractal dimension which is recently used for coastline determination.

\section{ACKNOWLEDGEMENTS}

This research was supported by the Basic Science Research Program through the National Research Foundation of Korea (NRF) funded by the Ministry of Education (2016R1D1A 1B03936246).

\section{REFERENCES}

Choi, J, H., 2005. Analysis and Application of Coastal Management System in Major Countries, Monthly Kore Maritime Institute, Korea, 250, pp. 79-104. 
Choi, S, H., Kim, J. C. and Lee, H. W., 2014. "The coastline length of Korea is $37 \%$, Ministry of Oceans and Fisheries", Korea,http://coast.mof.go.kr/coastNews/board/noticeBoardView.do?se $\mathrm{q}=1294$ (10 June. 2014).

Kim, H, E., 2016. "Change plan of Second Coastal Integrated Management Plan (2016 2021)", Korea, http://www.mof.go.kr/article /view.do?menuKey=375\&boardKey=9\&articleKey=14251 (16 Dec. 2016).

Sin, K, M., 2013. Main contents of the whole ocean functional compartment, Current issues of the chinese economy, China, 16(4), pp. $1-13$.

Sin, G, S., 2010. "Natural coast management goal", Korea, http://www.molit.go.kr/USR/policyTarget/dtl.jsp?idx=227(31 Dec. 2010). 